\title{
THE BREAKDOWN OF SELF-INCOMPATIBILITY IN CULTIVARS OF BRASSICA OLERACEA
}

\author{
K. F. THOMPSON and J. P. TAYLOR \\ Plont Breeding Institute, Combridge
}

Received r.iii.66

\section{INTRODUCTION}

THE wild ancestors of the cultivars of Brassica oleracea L., a diploid species $(2 \mathrm{n}=\mathrm{I} 8)$, are believed to have been self-incompatible. Some cultivars, however, have either preferential self-compatibility (summer cauliflowers) or partial to complete self-compatibility. In marrow-stem kale, which is morphologically relatively unspecialised and which has been less intensively inbred than cultivars in other botanical varieties of the species, self-compatibility is rare and is usually found only in inbreds homozygous for a $S$ allele, low in the dominance series (Thompson, 1961 and 1965$)$. This association in marrow-stem kale between self-compatibility and recessive $S$ alleles suggests that the more selfcompatible cultivars of other botanical varieties may have a high frequency of $S$ alleles, low in the dominance series and Thompson and Taylor (1965) did find that five $S$ alleles, low in the dominance series in marrow-stem kale, occurred frequently in some other botanical varieties. These earlier results have been extended by examining both a wider range of cultivars and more plants of each.

\section{MATERIAL AND METHODS}

The botanical varieties of $B$. oleracea and the sources of the stocks, from which plants were tested, are given below.

$$
\begin{aligned}
& \text { var. acephala - green marrow-stem kale (Cannell and Sons Ltd.) } \\
& \text { var. acephala -green dwarf curled kale (Bees Ltd.) } \\
& \text { var. capitata - January King cabbage (transplants-Cambridge market) } \\
& \text { var. capitata -Niggerhead cabbage (Charles Townsend Ltd.) } \\
& \text { var. gongyloides-Purple kohlrabi " Matouska Modra Rana” (Institut für }
\end{aligned}
$$

About ten flowers on each plant were selfed at the open flower stage to test for self-compatibility. All plants were tested for cross-incompatibility with pollen from four inbreds, homozygous respectively for the recessive alleles $S_{2}, S_{5}, S_{15}$, and $S_{28}$. At least four flowers were pollinated in each test-cross. The tests reveal the presence of these alleles because allele $S_{2}$ is active in the stigma in combination with any other $S$ allele and because alleles $S_{5}, S_{15}$, and $S_{28}$ are active in the stigma with about half of 
K. F. THOMPSON AND J. P. TAYLOR

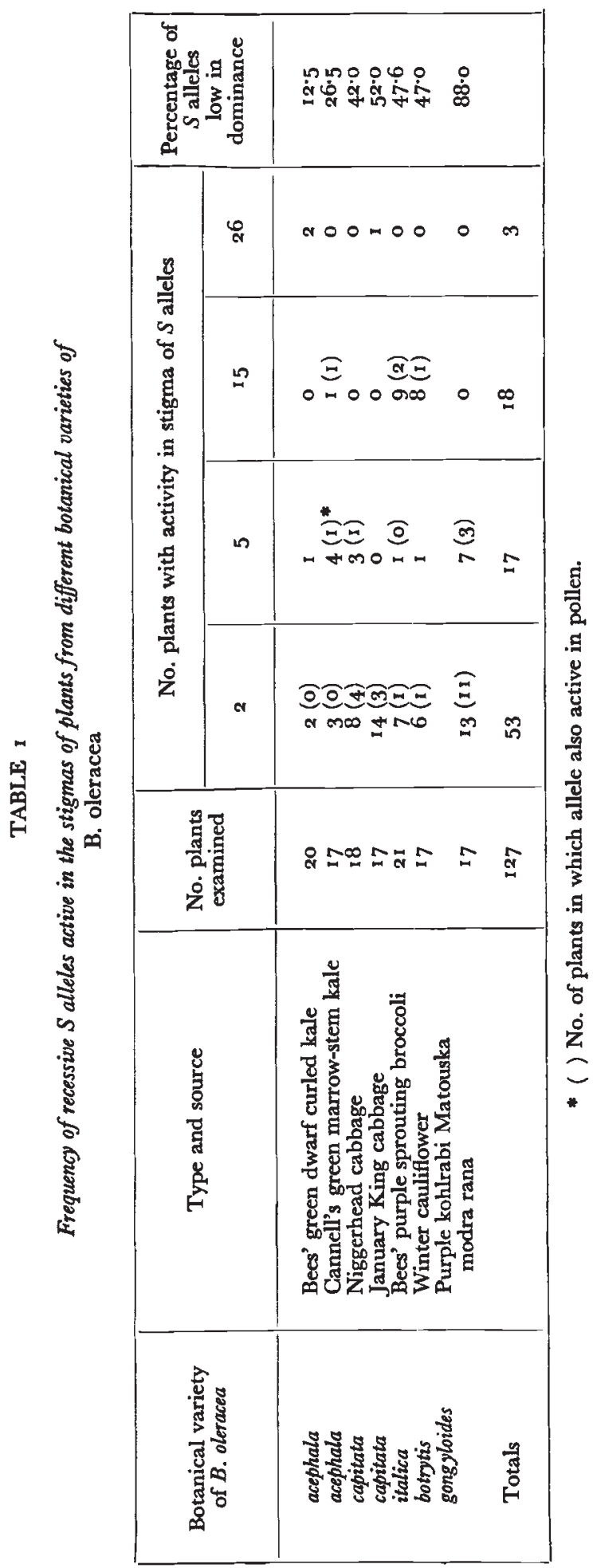


the other $S$ alleles with which they have been tested (Thompson and Taylor, 1966). If possible, incompatible and compatible pollinations were distinguished on the browning or darkening of stigmas, which occurs two days after a compatible pollination-see Thompson and Taylor (1966). The mean seed set per fruit was also recorded about six weeks after pollination and these results were checked with information on cross-incompatibility, obtained from colour changes in the stigma after pollination. If the stigmas of a plant did not darken clearly after a compatible cross, pollinations were classified as compatible or incompatible solely on the number of seed set per fruit. Clear darkening of stigmas after a compatible cross occurred in the majority of plants examined from marrow-stem kale, kohlrabi, January King cabbage and winter cauliflower, but this test could be used for very few plants of curled kale, red cabbage or purple sprouting broccoli. If stigmas darken after a compatible cross, the activity of self-incompatible $S$ alleles can be detected in self-compatible plants. The stigmas of a self-compatible plant normally fail to darken after selfing at the open flower stage or after an incompatible cross, although, in both instances, a full set of seed is produced. Fortunately, completely self-compatible plants were not found in varieties of curled kale, red cabbage or purple sprouting broccoli, in which darkening of the stigma is rare. However, none of the four recessive $S$ alleles could be identified in the summer cauliflower varieties " All the Year Round " and "Early Snowball", because all plants in both varieties were completely self-compatible and the stigmas of selfed flowers darkened as much as those crossed with the four tester inbreds.

If a plant has one of the recessive alleles, $S_{2}, S_{5}$, or $S_{15}$, it is easy to determine whether the other $S$ allele in the plant is also recessive. These three $S$ alleles were always recessive in the pollen in combination with twenty-three different $S$ alleles from marrow-stem kale (Thompson and Taylor, 1966). Activity of alleles $S_{2}, S_{5}$, or $S_{15}$ in the pollen indicates that the other $S$ allele in the plant is also very low in the dominance series. Nearly all plants, active for one of these recessive alleles in the stigma, were tested for activity of that allele in the pollen, and from this information the minimum percentages of recessive $S$ alleles in the populations (table I) were estimated.

\section{RESULTS}

The number of times the alleles $S_{2}, S_{5}, S_{15}$ and $S_{26}$ were active in the stigma in plants from stocks of different botanical varieties of $B$. oleracea is given in table $\mathrm{I}$. The number of plants, in which the alleles $S_{2}, S_{5}$ and $S_{15}$ were active in the pollen, as well as in the stigma, is shown in brackets. The percentage of $S$ alleles, low in dominance, for each stock examined, is also presented in table I.

The allele $S_{2}$ was found in every stock examined and in all botanical varieties. It was infrequent in Cannell's marrow-stem kale and in dwarf curled kale; but it was common in purple sprouting broccoli, winter cauliflower and Niggerhead or red pickling cabbage and a very high proportion of plants from January King cabbage and purple kohlrabi had this allele active in the stigma. This allele was usually recessive in the pollen, but it was active in the pollen from four of the eight plants, which had this allele, in Niggerhead cabbage. In Matouska kohlrabi $S_{2}$ was active in the pollen from at least I I of the I 3 plants, which had this allele. Alleles $S_{5}$ and $S_{15}$ occurred much less frequently than $S_{2}$. Allele $S_{5}$ was identified in all stocks except January King cabbage, but it occurred frequently only in the purple kohlrabi. Allele $S_{15}$ was surprisingly not recognised in Bees' stock of dwarf curled kale, although it had been earlier identified twice in dwarf curled kale 
selections (Thompson and Taylor, 1965). This allele was not found in purple kohlrabi, although it has been obtained from a variety of green kohlrabi, but it was common in both purple sprouting broccoli and in the winter cauliflower. Allele $S_{15}$ was only rarely active in the pollen and, on two of the four occasions, allele $S_{5}$ was present $\left(S_{15}\right.$ is dominant to $S_{5}$ in the pollen). The allele $S_{26}$ was not identified from Cannell's marrow-stem kale, in which it is known to occur rarely, but, as in the earlier series, it was found twice in dwarf curled kale and it was also active once in January King cabbage.

The percentage of recessive $S$ alleles in a stock can be determined from the number of times recessive $S$ alleles are active in the stigmas and also from the activity of these alleles in the pollen of plants, which have one of these recessive alleles active in the stigma. The activity of these $S$ alleles in the pollen was tested for all plants with the exception of a marrow-stem kale plant, active for $S_{2}$ in the stigma, a curled kale plant, which had $S_{5}$ and two winter cauliflower plants active for alleles $S_{5}$ and $S_{15}$ respectively. The percentage of $S$ alleles, low in dominance, cannot be estimated directly by adding together the figures given in table I for the number of recessive $S$ alleles in the stigma and the activity of these alleles in the pollen, because, particularly in Matouska kohlrabi, several plants were active in the stigma for two different recessive alleles. Some kohlrabi plants were heterozygous for alleles $S_{2}$ and $S_{5}$ (table 3); allele $S_{2}$ is dominant to $S_{5}$ in the pollen so that, if activity of these alleles in pollen and stigma were added together, the percentage of recessive $S$ alleles in the population would be overestimated. In fact, the figures given for the percentage of recessive $S$ alleles are probably too low, because other unknown recessive alleles might be active in plants, not active for any of the four tester $S$ alleles, and also because the alleles $S_{5}$ and $S_{15}$, in particular, might be recessive and therefore undetected in the stigma.

Neglecting these possible errors, considerable differences for the percentage of recessive $S$ alleles occurred between the different stocks. The lowest percentage of 12.5 was found in dwarf curled kale and the value of 26.5 per cent. for Cannell's marrow-stem kale was also low. Between 40 and 50 per cent. of the $S$ alleles were recessive in Niggerhead cabbage, January King cabbage, purple sprouting broccoli and in the winter cauliflowers but the highest value occurred in Matouska kohlrabi, in which 88 per cent. of the $S$ alleles were very low in dominance.

Plants were classified as self-compatible if the seed set on selfing at open flower was at least 80 per cent. of that set on bud pollination or 60 per cent. of that set from a compatible out-pollination. If the seed set on selfing varied between 40 and 80 per cent. of that set on bud pollination or between 25 and 60 per cent. of that set from a compatible outcross, the plant was described as partially self-compatible. It is assumed that most plants are heterozygous for recessive lethal genes and will set less seed on selfing than from a cross with an unrelated plant. 
Few partially self-compatible or completely self-compatible plants were found in marrow-stem kale, dwarf curled kale, purple sprouting broccoli or in Niggerhead cabbage (table 2). One of the two selfcompatible marrow-stem kale plants had the constitution $S_{5} S_{15}$ and in the other plant allele $S_{5}$ was active in the stigma (table 3 ). One dwarf curled kale plant, which had allele $S_{5}$ active in the stigma, was partially self-compatible, but the remaining plants were almost completely self-incompatible. One partially self-compatible plant from Niggerhead cabbage was heterozygous for $S_{2}$ and $S_{5}$ and in the other $S_{5}$ was active in pollen and stigma. Three of the 17 January King cabbages were self-compatible, one of these was heterozygous for $S_{2}$ and $S_{26}$. Partial self-compatibility was common in the kohlrabi, variety Matouska; four of the winter cauliflowers were self-compatible and another three were partially self-compatible.

\section{FREQUENCY OF $S$ ALLELES IN RELATION TO DOMINANCE RELATIONSHIPS}

The results given in this paper and also the earlier results of Thompson and Taylor (1965) show that the recessive alleles $S_{2}, S_{5}$ and $S_{15}$ are widely distributed throughout the botanical varieties of Brassica oleracea. The fourth recessive allele $S_{26}$ has, however, only been found rarely in marrow-stem kale, occasionally in curled kale and once only in January King cabbage. Allele $S_{2}$ occurs very commonly and is active in all botanical varieties and all stocks tested. Excluding marrow-stem kale, it is active in $4^{8}$ per cent. of all plants tested (table I). Alleles $S_{5}$ and $S_{15}$ are active in 12 per cent. and I 5 per cent. respectively. Whereas allele $S_{5}$ is found in all botanical varieties, allele $S_{15}$, although identified earlier in curled kale and green kohlrabi, was found in these tests only in purple sprouting broccoli and winter cauliflower; unlike allele $S_{5}$, it was as common in these stocks as $S_{2}$. The dominance relationships between these four $S$ alleles and also with other $S$ alleles offers a partial explanation for the differences in distribution and frequency.

Of 28 different $S$ alleles, obtained from marrow-stem and thousandhead kale and tested for dominance relationships by Thompson and Taylor (1966), only five were recessive in the pollen. Two of these alleles, $S_{21}$ and $S_{26}$, were recessive to about half the remaining $S$ alleles in the pollen, and three, $S_{2}, S_{5}$, and $S_{15}$, were recessive to all the other $S$ alleles with which they were tested. A simple linear dominance relationship, $S_{26}>S_{2}>S_{15}>S_{5}$, exists in the pollen between the four alleles, used for tests in this paper. In the stigma, $S_{5}, S_{15}$ and $S_{26}$ are recessive in about half the combinations tested, but $S_{2}$ is active in combination with all but two of the alleles tested. Allele $S_{2}$ is incompletely recessive with the two exceptional alleles. Even so, $S_{2}$ can always be recognised in the stigma. Thus, the outstanding characteristic of the three alleles, $S_{2}, S_{5}$, and $S_{15}$, is that they are pollen-recessive alleles and the fact that allele $S_{26}$ is only sometimes recessive in the 
pollen may account for the differences in frequency between this allele and $S_{5}$.

The activity of $S$ alleles, recessive in the pollen with the majority of other alleles, will normally be masked to permit compatible crosses between plants, heterozygous for the same recessive $S$ allele. Consequently, recessive $S$ alleles can be expected to occur more frequently than dominant $S$ alleles in a population. Sampson (personal communication, Jan. 26th 1965) found that the frequencies of pollenrecessive $S$ alleles were three times higher than those for dominant alleles in a wild population of Raphanus raphanistrum.

Although both $S_{2}$ and $S_{5}$ are widely distributed throughout $B$. oleracea, allele $S_{2}$ occurs at least three times as frequently as $S_{5}$. Allele $S_{2}$ is always active in the stigma in combination with any other $S$ allele and can be easily detected, whereas allele $S_{5}$ is recessive in the stigma with half the other $S$ alleles. Masking of the presence of $S_{5}$ cannot, however, account for the difference in frequencies between these two alleles. Allele $S_{5}$ is active in the stigma in combination with either $S_{2}$ or $S_{15}$ and these two alleles are active in about 60 per cent. of plants examined, excluding marrow-stem kale; hence only one fifth of the total number of $S_{5}$ alleles would be expected to be undetected in the populations. On the other hand, allele $S_{5}$ might be anticipated to be more frequent than $S_{2}$ in these populations, because $S_{2}$ is dominant to $S_{5}$ in the pollen and is always active in the stigma. However, allele $S_{2}$ occurs twice as frequently as $S_{5}$ in the purple kohlrabi, which has a very high percentage of recessive $S$ alleles in the population and in which allele $S_{2}$ is normally active in pollen and stigma. It is possible that $S_{2}$ has other inherent selective advantages.

Allele $S_{15}$ is found in fewer stocks than $S_{5}$, but when it occurs, the frequency of this allele in a population is comparable to that of allele $S_{2}$. Although plants, homozygous for alleles $S_{2}$ or $S_{15}$ can be very selfincompatible, competition occurs between these alleles and the $S$ allele heterozygote is self-compatible (Thompson, 1965). In earlier work, one plant of purple sprouting broccoli was found to be-selfcompatible and to be heterozygous for these two alleles. This may explain the high frequencies of allele $S_{15}$ in populations also active for $S_{2}$. As suggested in section 6 , the frequencies of $S$ alleles, associated with self-compatibility, would be expected to increase in rigorously selected cultivars, based on relatively few selections.

\section{PERCENTAGE OF RECESSIVE $S$ ALLELES IN STOCKS AND THE OCCURRENCE OF SELF-COMPATIBILITY}

Stocks of different botanical varieties vary considerably in the frequency of recessive $S$ alleles (table I). In marrow-stem kale, selfcompatibility has often been found in selections or inbreds, in which only $S$ alleles, low in the dominance series, are present. The selfcompatibility factors are genetically independent of the self-incompatibility system and self-compatibility is usually expressed only in the 


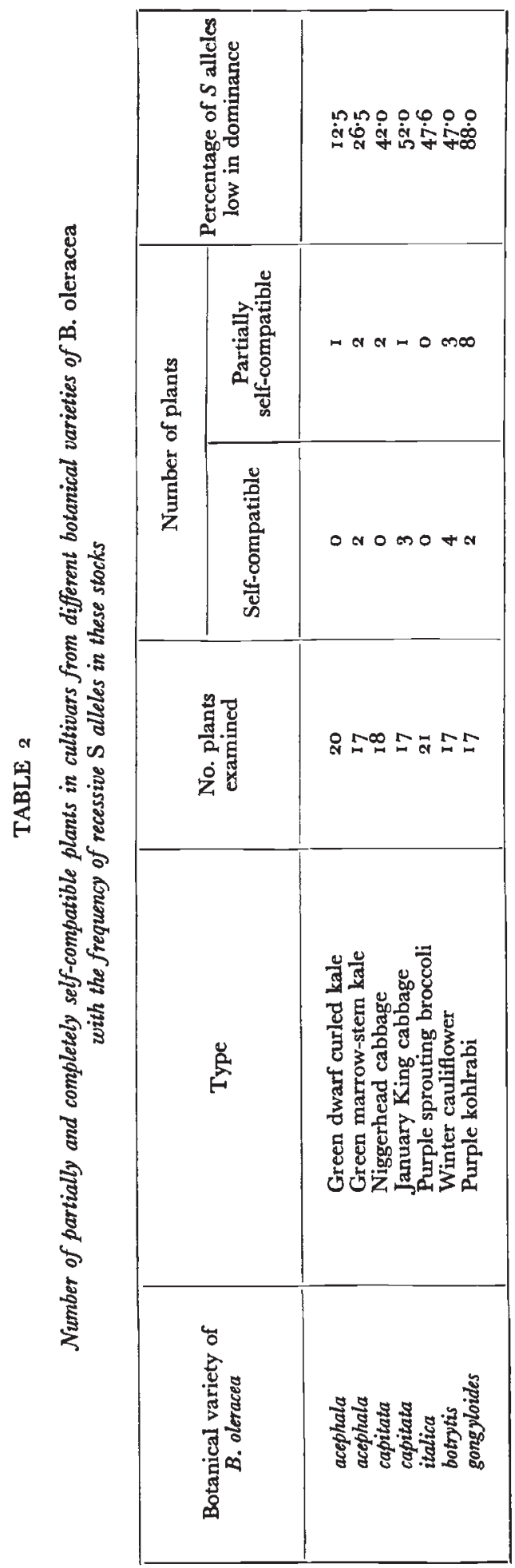


absence of $S$ alleles, high in the dominance series (Thompson, $196_{1}$, I 965 ). However, self-compatibility has occasionally occurred in plants, active for a dominant $S$ allele. It is, therefore, of interest to compare the percentage of recessive $S$ alleles in different stocks with the occurrence of partial and complete self-compatibility.

Self-compatibility is less common in stocks than recessive $S$ alleles, and, for this reason, is more liable to sampling error. Thus the numbers of self-compatible plants for marrow-stem kale in table 2 are higher than would be expected from the proportion of selections, taken from this stock for breeding purposes, which are self-compatible. Other

TABLE 3

$\mathrm{S}$ allele constitution of partially and completely self-compatible plants from different botanical varieties of $\mathrm{B}$. oleracea

\begin{tabular}{|c|c|c|c|}
\hline \multirow{2}{*}{$\begin{array}{l}\text { Botanical } \\
\text { variety of } \\
B . \text { oleracea }\end{array}$} & \multirow{2}{*}{ Type } & \multicolumn{2}{|c|}{$S$ allele constitution of plants } \\
\hline & & Self-compatible & $\begin{array}{c}\text { Partially } \\
\text { self-compatible }\end{array}$ \\
\hline $\begin{array}{l}\text { acephala } \\
\text { acephala } \\
\text { capitata } \\
\text { capitata } \\
\text { botrytis } \\
\text { gongyloides }\end{array}$ & $\begin{array}{l}\text { Green dwarf curled kale } \\
\text { Green marrow-stem kale } \\
\text { Niggerhead cabbage } \\
\text { January King cabbage } \\
\text { Winter cauliflower } \\
\text { Purple kohlrabi }\end{array}$ & $\begin{array}{l}S_{\mathrm{D}} S_{\mathrm{b}} ; S_{\mathrm{b}} S_{15} \\
S_{2} S_{28} ; S_{2} S_{23} ; S_{\mathrm{D}} S_{2} \\
S_{2} S_{15} ; S_{\mathrm{D}} S_{2} ; S_{\mathrm{D}} S_{5} \\
S_{\mathrm{D}} S_{15} \\
S_{5} S_{\mathrm{R}} ; S_{\mathrm{D}} S_{\mathrm{D}}\end{array}$ & $\begin{array}{l}S_{\mathrm{D}}^{*} S_{5} \\
S_{\mathrm{D}} S_{5} ; S_{\mathrm{D}} S_{\mathrm{D}} \\
S_{2} S_{6} ; S_{5} S_{\mathrm{R}}^{\dagger} \\
S_{2} S_{23} \\
S_{\mathrm{D}} S_{15} ; S_{\mathrm{D}} S_{15} ; S_{\mathrm{D}} \\
S_{\mathrm{D}} \\
\text { Five plants } S_{2} S_{\mathrm{R}} \\
\text { Three plants } S_{2} S_{5}\end{array}$ \\
\hline
\end{tabular}

* $S_{\mathrm{D}}$ - unidentified $S$ allele; in heterozygotes dominant to recessive $S$ alleles in pollen.

$\dagger S_{\mathrm{R}}$ - unidentified $S$ allele; with which recessive $S$ allele is active in pollen.

botanical varieties of $B$. oleracea have a much higher proportion of recessive $S$ alleles than marrow-stem or dwarf curled kale from var. acephala. Dwarf curled kale and purple kohlrabi had respectively the lowest and highest percentages of recessive alleles of the stocks tested. Only one of the curled kale plants was partially self-compatible, but more than half of the kohlrabi plants were either partially or completely self-compatible. Four stocks had from 40 to 50 per cent. of recessive $S$ alleles, but January King cabbage and winter cauliflower had more self-compatible plants than purple sprouting broccoli and red cabbage. A dominant allele was present in the majority of plants from these four stocks, because, with the exception of allele $S_{2}$ in red cabbage, the tester $S$ alleles were rarely active in the pollen.

The $S$ allele constitution of partially and completely self-compatible plants are given in table 3 . As mentioned at the end of section 3 , several of the self-compatible plants in marrow-stem kale, January King and red cabbage had only recessive $S$ alleles. Eight partially self-compatible and the completely self-compatible plant from the purple kohlrabi had only recessive $S$ alleles; one completely self-compatible plant was not 
active for any of the four recessive tester $S$ alleles and was recorded in table 3 as $S_{\mathrm{D}} S_{\mathrm{D}}$. However, this plant might have been active for a different recessive $S$ allele. One self-compatible plant from winter cauliflower was heterozygous for alleles $S_{2}$ and $S_{15}$, but the other three self-compatible plants each had an $S$ allele, dominant either to $S_{2}, S_{5}$, or $S_{15}$ in the pollen. At least two different dominant alleles occurred in these three plants. Four plants from January King cabbage were heterozygous for alleles $S_{2}$ and $S_{23}$, in which $S_{23}$ was dominant to $S_{2}$ in the pollen. One of these four plants was completely self-compatible and two were very self-incompatible. Allele $S_{23}$ may also be fairly low in the dominance series, because alleles $S_{2}$ and $S_{23}$ were both active in the pollen from a wild cabbage plant. All purple sprouting broccoli plants were very self-incompatible, except for one self-compatible plant from the earlier series, which was heterozygous for alleles $S_{2}$ and $S_{15}$. It is possible that self-compatible genes are rare in purple sprouting broccoli.

Although self-compatible plants in different botanical varieties of $B$. oleracea often carry only recessive $S$ alleles, some self-compatible plants have alleles, higher than the pollen-recessive alleles in the dominance series, but the position of these dominant alleles, e.g. $S_{23}$, in the dominance series may still be relatively low. Thus, although the frequency of recessive $S$ alleles is not always matched by the degree of self-compatibility in individual stocks, there appears to be a tendency for selfcompatibility to be more common in varieties with a high proportion of recessive $S$ alleles.

\section{EFFECTS OF INTENSIVE SELECTION ON THE FREQUENCY OF RECESSIVE $S$ ALLELES AND SELF-COMPATIBILITY IN B. OLERACEA}

The different frequencies of recessive alleles and the association between self-compatibility and a high frequency of recessive alleles can be explained by the effect of intensive selection in certain botanical varieties of $B$. oleracea. When plants of $B$. oleracea were first taken into cultivation, they were probably highly self-incompatible. Thus Sampson (I964) has found that one striking difference between two crop species (broccoli and radish) and two wild species (Lesquerella densipila and Raphanus raphanistrum) was "the commonness of self-compatible individuals in the crops and their absence from the weeds."

The agricultural kales, and perhaps curled kales, are morphologically relatively unspecialised and have been less intensively bred than the other botanical varieties. Mass-selected stocks of marrow-stem kale may be based on several hundred selections. In marrow-stem kale self-compatibility is rare and at least 24 different $S$ alleles have been identified in one stock, although only $\mathrm{I}_{5}$ of these occurred frequently (Thompson and Taylor, 1966). Similarly, plants of dwarf curled kale were very self-incompatible and no dominant allele occurred more than three times in the 20 plants tested.

In wild populations, masking of the activity of recessive $S$ alleles 
permits a much higher frequency of recessive than dominant $S$ alleles. In the weed species, Raphanus raphanistrum, Sampson (personal communication, Jan. 28th 1965) found that three pollen-recessive alleles had a mean frequency three times that of four dominant $S$ alleles. Under cultivation, in which small numbers of selected plants are seeded together, there would be a greater selection pressure than in the wild. The total number of $S$ alleles in the population would fall as the proportion of recessive $S$ alleles increased. If self-compatible genes, independent of the $S$ allele system, were present, seed multiplication would favour the retention of partially or completely self-compatible plants with $S$ alleles, low in the dominance series, especially if insect pollinators were rare.

Stocks of January King cabbage, purple sprouting broccoli, winter cauliflower, red cabbage and probably Brussels sprouts are at this stage in the breakdown of the self-incompatibility system. In many of these stocks the number of different dominant $S$ alleles has been reduced. Only five different dominant $S$ alleles were found in the I 7 plants of January King cabbage examined; allele $S_{23}$ was active in four plants and another dominant allele was active in five plants. In winter cauliflower one dominant $S$ allele was active in seven of the I 7 plants and in red cabbage one dominant allele was identified in seven of the I8 plants.

A further stage towards a self-fertilised crop is shown in the purple kohlrabi variety "Matouska," in which dominant $S$ alleles are almost absent and 88 per cent. of the $S$ alleles are recessive and represented mainly by alleles $S_{2}$ and $S_{5}$. Partial and complete self-compatibility is common, but self- or cross-incompatible pollinations can still be distinguished from cross-compatible pollinations, by the failure of stigmas to darken after pollination. Finally, the summer cauliflowers represent the most self-compatible type in $B$. oleracea, in which it is not possible to distinguish incompatible from compatible crosses on darkening of stigmas, because the stigmas of selfed flowers darken considerably. For this reason, $S$ alleles in two varieties of summer cauliflower could not be identified. Watts $(1965)$ found that there is little if any inbreeding depression in summer cauliflowers in contrast to the more self-incompatible autumn and winter cauliflowers, in which even selfcompatible plants showed marked inbreeding depression on selfing. He said that " records of summer cauliflower production can be traced to the middle of the I 9 th century, prior to which only the coarser autumn and winter types seem to have been grown. It is highly possible that the increasing interest in horticulture at that time led to the selection of an " annual" earlier maturing type, which, under continuous close selection and mating evolved a system of homozygous balance."

The evolution of self-compatibility in the summer cauliflower may be paralleled by the breeding of the winter cauliflower cultivar, Cambridge Dwarf April, which was obtained by rigid selection over the last 
thirty years following a cross between two plants of the winter cauliflower cultivar St George (Watts, I963). The results of tests for activity of recessive $S$ alleles in plants from the cultivar, St George, are given in this paper (table I), and Watts considered this cultivar to be one of the most self-incompatible of the winter cauliflowers. Watts found that Cambridge Dwarf April was the only cultivar from the winter cauliflowers to set more seed by self than by mixed pollen. He also states that this cultivar is " noticeably uniform and yields well, showing no loss of vigour after successive generations of inbreeding."

\section{INTERPRETATION OF DISTRIBUTION AND FREQUENCY OF ALLELE $S_{2}$ IN B. OLERACEA}

Allele $S_{2}$ has been found in all stocks of any botanical variety of $B$. oleracea, in which at least $I 7$ plants were tested. The total number of plants, in which this allele has been identified, is surprisingly high, and the frequency of this allele in January King cabbage, Niggerhead cabbage and purple kohlrabi is probably even higher than is suggested by data in table $\mathrm{I}$. In these stocks, plants, in which $S_{2}$ is active in the pollen and $S_{5}$ or $S_{15}$ are not identified, are probably homozygous for allele $S_{2}$. Reasons for the widespread distribution and high frequency of this allele in $B$. oleracea must be considered.

Plants from all the different botanical varieties of $B$. oleracea cross readily with each other to give fertile hybrids. However, as suggested by Thompson and Taylor (rg65) it is unlikely that allele $S_{2}$ has been spread in the last century by cross-pollination between the distinct, basic, breeders' stocks of Brussels sprouts, cabbages, kohlrabi, purple sprouting broccoli or cauliflower. Although mutations are normally recessive and the number of different recessive $S$ alleles in $B$. oleracea appears to be limited, independent mutation to $S_{2}$ in different botanical varieties is not probable, because $S$ alleles are remarkably stable. Lewis (I95I) reported no new self-incompatible mutations at the $S$ locus after screening 22 million gametes of Oenothera and Dodds (rg6r) found the same $S$ alleles in diploid cultivated species of potato and in polyhaploids of autotetraploid Andigena potatoes which must have been isolated for a long time. It is much more likely that allele $S_{2}$, and perhaps $S_{5}$ and $S_{15}$, occurred in the ancestral $B$. oleracea, from which the modern botanical varieties have evolved.

The widespread occurrence of the three pollen-recessive alleles $S_{2}$, $S_{5}$ and $S_{15}$ in different botanical varieties of $B$. oleracea can be satisfactorily explained by the effect of intensive selection on the frequency of recessive $S$ alleles in populations. It does not account for the very high frequency and ubiquitous distribution of allele $S_{2}$, relative to alleles $S_{5}$ and $S_{15}$. Some horticultural cultivars are based on very few selections and it would be expected that by chance one or other of the pollen-recessive $S$ alleles would be eliminated sometimes from a stock. This would appear to happen to alleles $S_{5}$ and $S_{15}$. From table I, allele $S_{15}$ was not detected in January King cabbage, red cabbage or in 
the purple kohlrabi variety, while $S_{5}$ was not found in January King cabbage. The self-compatibility of the heterozygote, $S_{2}, S_{15}$ confers an advantage on alleles $S_{2}$ and $S_{15}$, compared with allele $S_{5}$, but it is allele $S_{15}$, which most frequently was not found in stocks. Otherwise the dominance relationships of allele $S_{2}$ do not give it any advantage compared with the other two alleles and it must be assumed that allele $S_{2}$ must have some other inherent advantages.

\section{SUMMARY}

I. Three pollen-recessive $S$ alleles, $S_{2}, S_{5}$ and $S_{15}$, which were identified in marrow-stem kale, are frequently active in the stigmas of a wide range of botanical varieties within the species Brassica oleracea.

2. Populations from different varieties differed in the frequency of recessive $S$ alleles (table I). High frequencies of recessive $S$ alleles in a population are often associated with a higher proportion of partially and completely self-compatible plants.

3. Intensive selection for morphological and physiological characters by plant breeders is probably responsible for both these properties.

4. Allele $S_{2}$ was found more commonly than the other pollenrecessive alleles and has been recognised from all the botanical varieties examined. This allele was active in $4^{8}$ per cent. of plants tested, apart from marrow-stem kale. It may have been present in the ancestral $B$. oleracea, from which the modern botanical varieties have evolved.

\section{REFERENCES}

DoDDs, K. S. I961. Ann. Rep. Fohn Innes Institute, 52, 22.

LEWIS, D. 1951. Structure of the incompatibility gene. III. Types of spontaneous and induced mutations. Heredity, 5, 399-414.

SAMPSON, D. R. 1964. A one-locus self-incompatibility system in Raphanus raphanistrum. Can. F. Genet. Cytol., 6, 435-445.

тномрson, к. F. 1961. Ann. Rep. Plant Breeding Institute, Cambridge, (1959-1960), 41. тном pson, к. F. 1965. Ann. Rep. Plant Breeding Institute, Cambridge, (1963-1964), 7 I. THOMPSON, K. F., AND TAYLOR, J. P. I965. Identical $S$ alleles in different botanical varieties of Brassica oleracea. Nature, 208, 306-307.

THOMPSON, K. F., AND TAYLOR, J. P. I966. Non-linear dominance relationships between $S$ alleles in kale. Heredity, 21, 345-362.

WATTS, L. E. 1963. Investigations into the breeding system of cauliflower, Brassica oleracea var. botrytis (L.). I. Studies of self-incompatibility. Euphytica, 12, 323340.

WATTS, L. E. 1965 . Investigations into the breeding system of cauliflower. II. Adaptation of the system to inbreeding. Euphytica, 14, 67-77. 